\title{
Mechanism of 3,3'-Disulfopropyl-5,5'-Dichloro
}

\section{Thiacyanine Anion Interaction With Citrate-Capped}

\section{Silver Nanoparticles: Adsorption and J-aggregation}

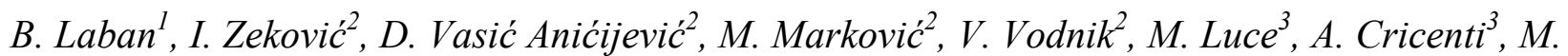

Dramićanin $^{2}, V$. Vasić$^{2} *$

${ }^{1}$ Faculty of Natural Science and Mathematics, University of Priština, LoleRibara 29, 38220

Kosovska Mitrovica, Serbia

${ }^{2}$ Vinča Institute of Nuclear Sciences, University of Belgrade, P.O. Box 522, Belgrade, Serbia

${ }^{3}$ Istituto di Struttura della Materia, Consiglio Nazionale delle Ricerche, Roma, Italy

*Corresponding author: evasic@vinca.rs; Tel: (+381 11) 3408 287; Fax: (+381 11) 244-7207 


\section{EXPERIMENTAL SECTION}

Details concerning apparatus and performing experiments:

\section{TEM measurements}

The samples for TEM observations were prepared by putting a small amount of the colloidal solution on the carbon-supported copper grids, and then drying in air. For each sample, the size of more than 200 particles in the TEM images was measured to obtain the average particles size.

\section{DLS and electrophoretic measurements}

The medium viscosity, medium refractive index and material refractive index were $0.8872 \mathrm{mPa} \cdot \mathrm{s}, 1.330$ and 1.200 , respectively. The measurements were performed at $25^{\circ} \mathrm{C}$. The particle size was determined by DLS technique applying backscatter detection $\left(173^{\circ}\right.$ detection optics). Disposable polystyrene size cuvettes (Sarstedt, Germany), filled with $1 \mathrm{ml}$ of sample, were used. For size determinations, the instrument was checked by measuring particle size standards (polystyrene microspheres in water, 60 and $220 \mathrm{~nm}$ particle mean diameters, Nanosphere ${ }^{\mathrm{TM}}$ Size Standards, Duke Scientific Corporation, USA). Ten consecutive measurements were performed, and the mean value was recorded. Cumulant analysis resulted in mean particle size (z-average) and polydispersity index (PdI) values were used for particle size results interpretation. 
The Laser Doppler Electrophoresis (LDE) method, as a combination of electrophoresis and Laser Doppler Velocimetry (LDV), was applied to measure electrophoretic mobility of sample particles and ZP was calculated according to Henry's equation. ZP measurements were performed in size and ZP folded capillary cells (Malvern Instruments, UK) and ZP Transfer standard (-50 mV, Malvern Instruments, UK) was used as a check standard. Ten consecutive measurements were performed for each sample and the average ZP value was displayed.

\section{AFM measurements}

Air operating atomic force scanning tunneling microscope suitable to study semiconductors, metals and biological samples was used. The lateral friction images (not shown) have been found very powerful because of their sensitivity to the small structures that protrude from a large corrugated surface. The drop of sample was put on the glass surface and dried at $37^{\circ} \mathrm{C}$ for one hour. Data have been treated by only a background subtraction and then analyzed using Gwiddion software.

\section{DFT calculations}

Both TC dye and citrate were modelled as anions while the negative charge was compensated with the uniform positive background. Thresholds for electronic and force convergence were set to $10^{-5} \mathrm{eV}$ and $1.5 \times 10^{-3} \mathrm{eV} / \mathrm{Bohr}$, respectively. Following the common practice, DFT binding energies were calculated from the energy difference between final state and the sum of isolated starting components (here, citrate or TC dye anions, and Ag). 
a)

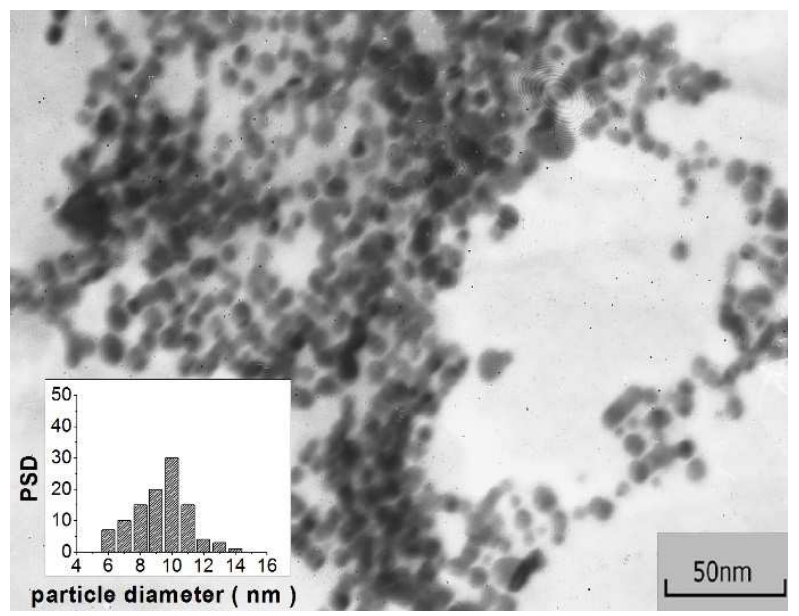

b)

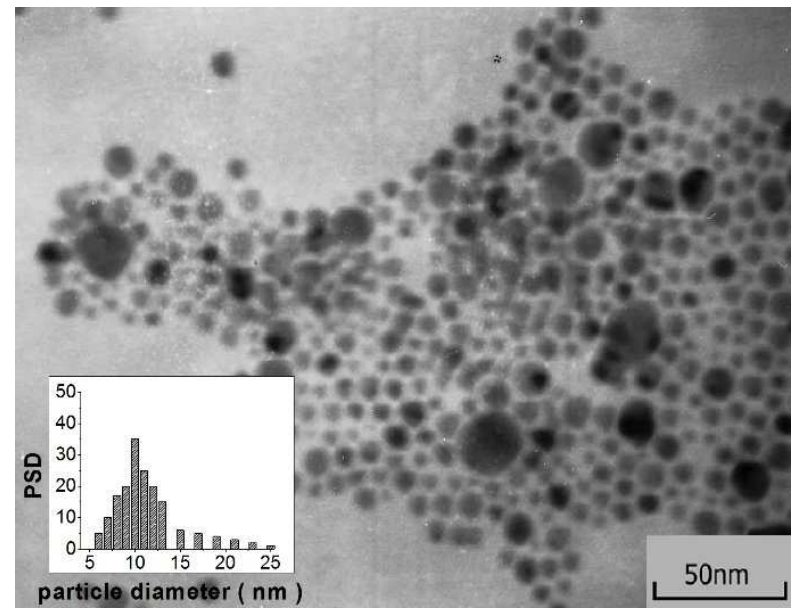

Figure S1. TEM micrographs of bare (a) and TC coated (b) AgNPs. Inset: particle size distribution (PSD). 
Table S1. Energetic of possible $\mathrm{K}^{+}$ions reactions with citrate and TC dye on AgNPs surface. To model a $\mathrm{K}^{+}$hydration sphere, 6 water molecules were taken into account.

\begin{tabular}{|c|c|c|c|}
\hline & Reaction type & Reaction & Energy / eV \\
\hline 1 & dehydration & $\mathrm{K}\left(\mathrm{H}_{2} \mathrm{O}\right)_{6}{ }^{+} \rightarrow \mathrm{K}^{+}+6 \mathrm{H}_{2} \mathrm{O}$ & +1.54 \\
\hline 2 & dehydration & $2 \mathrm{~K}\left(\mathrm{H}_{2} \mathrm{O}\right)_{6}{ }^{+} \rightarrow 2 \mathrm{~K}^{+}+12 \mathrm{H}_{2} \mathrm{O}$ & +3.08 \\
\hline 3 & addition & $\mathrm{K}^{*}$ citrate $^{*} \rightarrow \mathrm{K}^{*}$-citrate & -2.71 \\
\hline 4 & addition & $2 \mathrm{~K}^{+}+$citrate $^{*} \rightarrow \mathrm{K}_{2}^{*}$-citrate $^{*}$ & -2.81 \\
\hline 5 & addition & $3 \mathrm{~K}^{+}+$citrate $^{*} \rightarrow \mathrm{K}_{3}^{*}$-citrate & -1.48 \\
\hline 6 & addition & $\mathrm{K}^{+}+\mathrm{TC}^{*}$ & +6.44 \\
\hline 7 & exchange & $\mathrm{K}^{*}$-citrate $^{*}+\mathrm{TC} \rightarrow \mathrm{TC}^{*}+\mathrm{K}$-citrate & +0.87 \\
\hline
\end{tabular}

Energy of reactions: reaction (1) $\quad-\Delta \mathrm{E}=+1.54 \mathrm{eV}$

$$
\begin{aligned}
& \text { reaction (3) }-\Delta \mathrm{E}=-2.71 \mathrm{eV} \\
& \text { reaction (7) }-\Delta \mathrm{E}=+0.87 \mathrm{eV}
\end{aligned}
$$

Total energy: $-0.30 \mathrm{eV}$

$\begin{array}{ccc}\text { Energy of reactions: } & \text { reaction (2) } & -\Delta \mathrm{E}=+3.08 \mathrm{eV} \\ & \text { reaction (4) } & -\Delta \mathrm{E}=-2.81 \mathrm{eV} \\ & \text { reaction (7) } & -\Delta \mathrm{E}=+0.87 \mathrm{eV}\end{array}$

Total energy: $-0.52 \mathrm{eV}$ 
The results show that the attractive interaction between adsorbed citrate and $\mathrm{K}^{+}$ions provides a thermodynamical driving force to drive at least one $\mathrm{K}^{+}$ion per adsorbed citrate out of its hydration sphere and deposit it onto the AgNP surface. Interaction between adsorbed TC dye and $\mathrm{K}^{+}$ions requires $6.44 \mathrm{eV}$, it is not energetically favourable and does not impact $\mathrm{TC}$ dye adsorption on the AgNP surface 


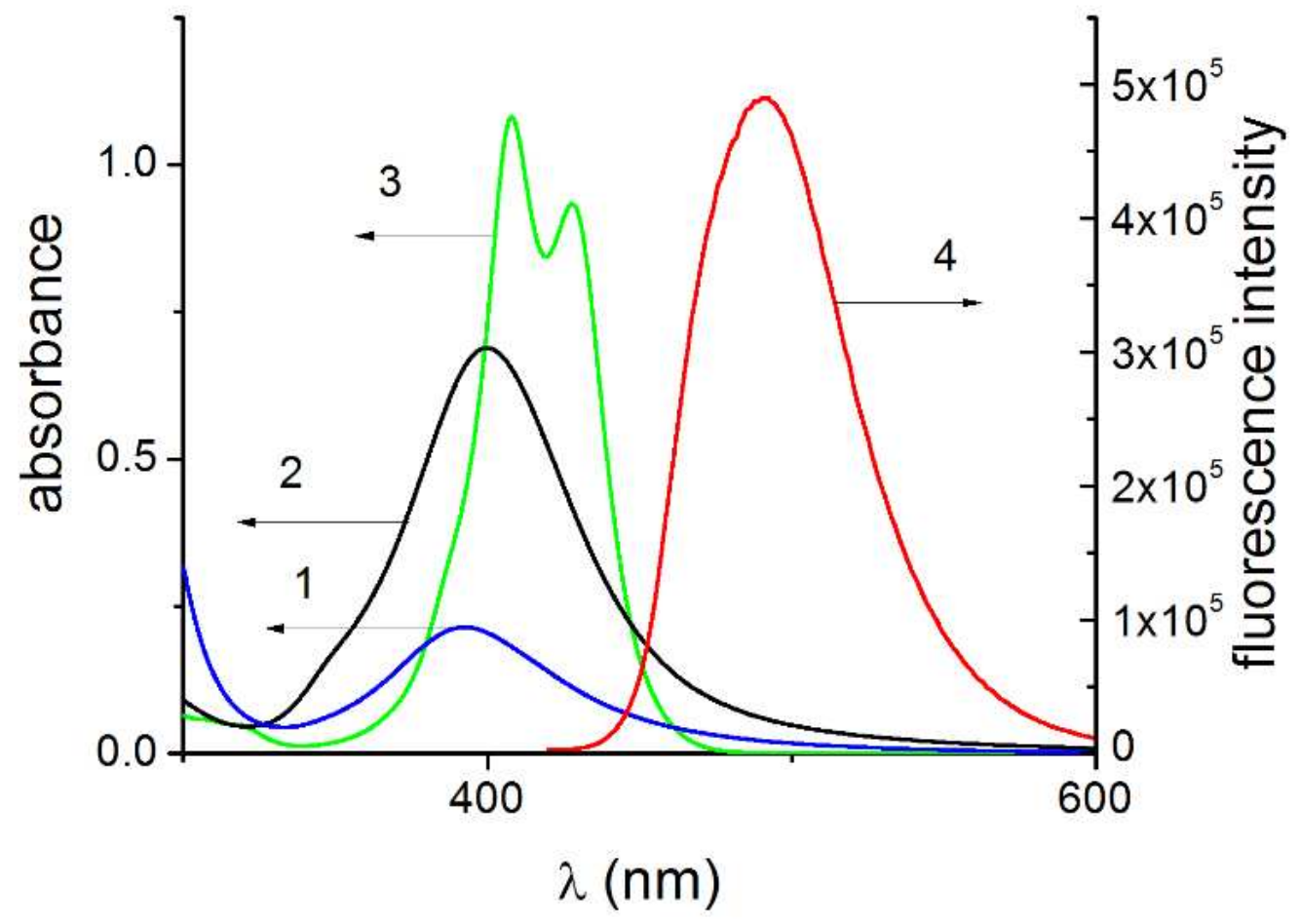

Figure S2. Absorption spectra of $0.73 \times 10^{-9} \mathrm{M} \operatorname{AgNPs}(1), 2.17 \times 10^{-9} \mathrm{M} \operatorname{AgNPs}(2), 1.6 \times 10^{-}$ ${ }^{5} \mathrm{M}$ TC (3), and fluorescence spectrum of $1.6 \times 10^{-5} \mathrm{M}$ TC in the presence of $3 \times 10^{-4} \mathrm{M} \mathrm{KCl}(4)$ 


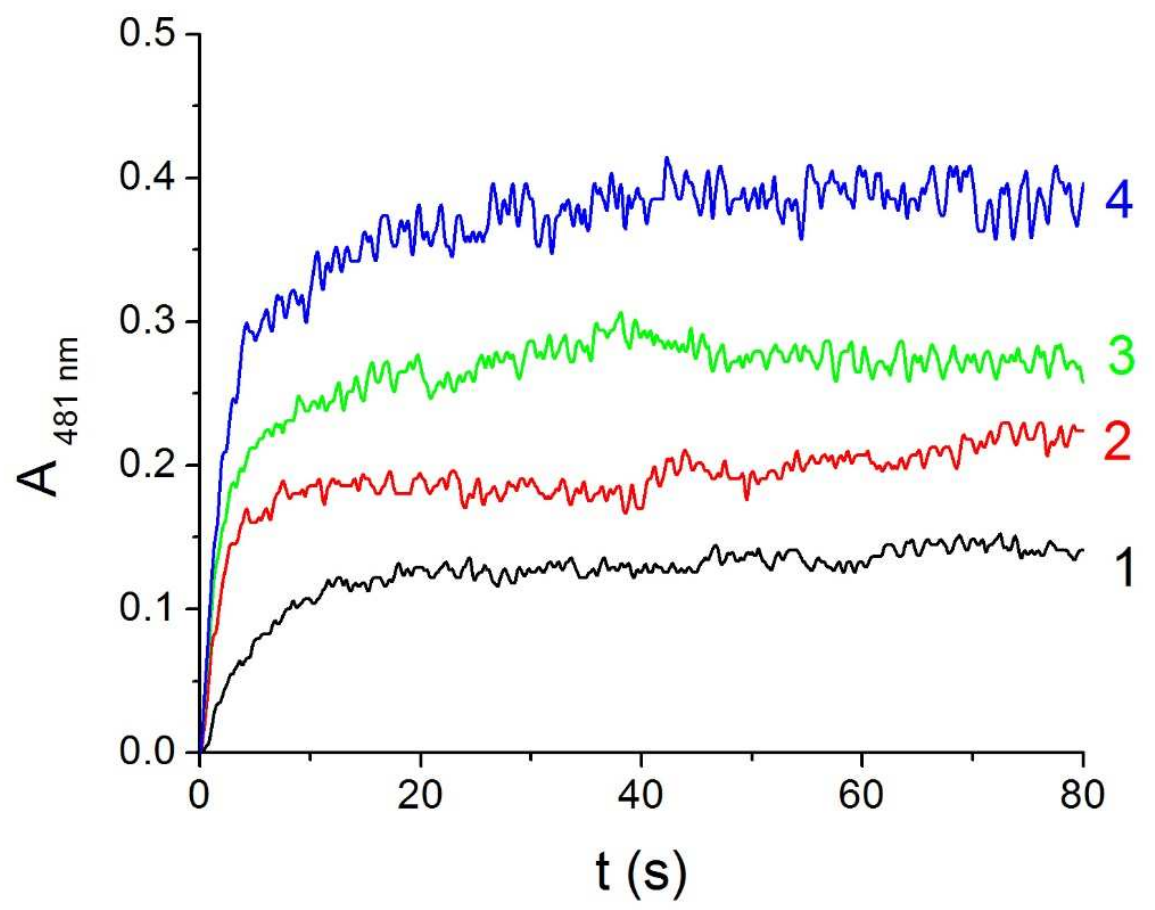

Figure S3. Kinetic curves of the reaction between $1 \times 10^{-5} \mathrm{M}$ TC and $2.2 \times 10^{-9}(1), 3.2 \times 10^{-9} \mathrm{M}$ (2), $4.3 \times 10^{-9} \mathrm{M}(3)$ and $6.5 \times 10^{-9} \mathrm{M}(4) \mathrm{AgNPs}$, in the presence of $1 \times 10^{-3} \mathrm{M} \mathrm{KCl}$.

Table S2. Rate constants for $1 \times 10^{-5} \mathrm{M}$ TC adsorption and J-aggregation on AgNPs surface

\begin{tabular}{|c|c|c|c|c|c|}
\hline $\begin{array}{c}\text { AgNPs } \\
\mathrm{x} 10^{-9}(\mathrm{M})\end{array}$ & $\begin{array}{c}\mathrm{t}_{1 / 2}{ }^{1} \\
(\mathrm{~s})\end{array}$ & $\begin{array}{c}\mathrm{t}_{1 / 2}{ }^{2} \\
(\mathrm{~s})\end{array}$ & $\mathrm{k}_{\mathrm{obs} 1}\left(\mathrm{~s}^{-1}\right)$ & $\mathrm{k}_{\mathrm{obs} 2}\left(\mathrm{~s}^{-1}\right)$ & $\Delta \mathrm{A}$ \\
\hline 2.2 & $1.08 \pm 0.19$ & $8.37 \pm 1.08$ & 0.92 & 0.12 & 0.098 \\
\hline 4.3 & $1.30 \pm 0.12$ & $9.96 \pm 1.17$ & 0.77 & 0.10 & 0.276 \\
\hline 6.5 & $1.72 \pm 0.12$ & $15.01 \pm 2.1$ & 0.58 & 0.07 & 0.390 \\
\hline 10.0 & $1.89 \pm 0.13$ & $18.75 \pm 2.2$ & 0.27 & 0.019 & 0.451 \\
\hline
\end{tabular}


a)

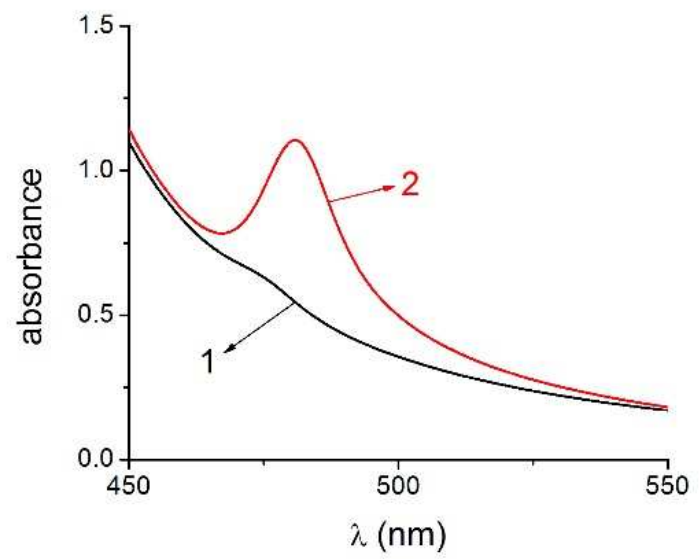

b)

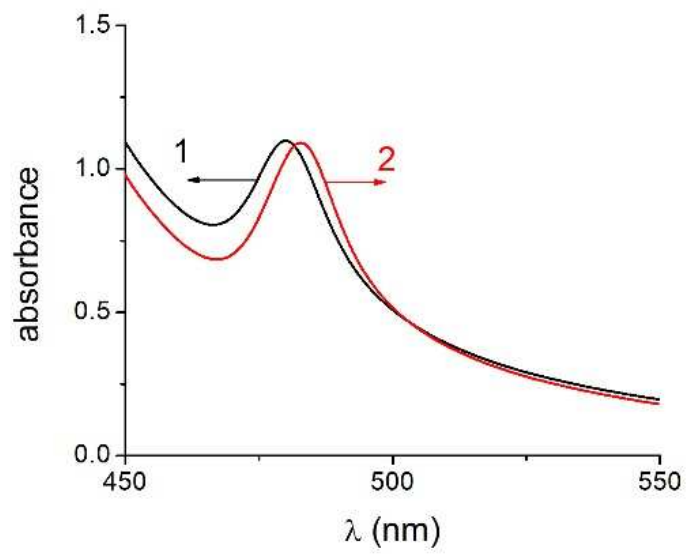

Figure S4. Absorption spectra of J-aggregate in the presence of $3.3 \times 10^{-4} \mathrm{M} \mathrm{KCl}$ (a) and $2 \times 10^{-3}$ $\mathrm{M} \mathrm{KCl}$, immediately after mixing solutions (line 1) and after 24h (line 2).Concentrations of $\operatorname{AgNPs}\left(1 \times 10^{-8} \mathrm{M}\right)$ and TC $\left(1 \times 10^{-5} \mathrm{M}\right)$ were constant. 